arteries could be obscured by normal or increased production in the microcirculation. Our findings, if applicable to man, suggest that diminished $\mathrm{PGI}_{2}$ production may have a role in the increased propensity of diabetics to atherosclerosis but is less likely to be important in the pathogenesis of microangiopathy.

This work was supported by the Life Insurance Research Fund of Australia, Department of Veterans' Affairs, and a grant to Professor T J Martin from the National Heart Foundation of Australia.

\section{References}

${ }^{1}$ Harrison HE, Reece AH, Johnson M. Decreased vascular prostacyclin in experimental diabetes. Life Sci 1978;23:351-5.

2 Harrison HE, Reece AH, Johnson M. Effect of insulin treatment on prostacyclin in experimental diabetes. Diabetologia 1980;18:65-8.

${ }^{3}$ Carreras LO, Chamone DAF, Klerckx P, Vermylen J. Decreased vascular prostacyclin $\left(\mathrm{PGI}_{2}\right)$ in diabetic rats. Stimulation of $\mathrm{PGI}_{2}$ release in normal and diabetic rats by the antithrombotic compound Bay $g 6575$. Thromb Res 1980;19:663-70.

4 Subbiah MTR, Deitemeyer D. Altered synthesis of prostaglandins in platelet and aorta from spontaneously diabetic Wistar rats. Biochem Med $1980 ; 23: 231-5$

5 Gerrard JM, Stuart MJ, Rao GHR, et al. Alteration in the balance of prostaglandin and thromboxane synthesis in diabetic rats. $\mathcal{F}$ Lab Clin Med 1980;95:950-8.

${ }^{6}$ Rogers SP, Larkins RG. Production of 6-oxo-prostaglandin $F_{1 \alpha}$ by rat aorta: influence of diabetes, insulin treatment and caloric deprivation. Diabetes $1981 ; 30: 935-9$.

${ }^{7}$ Moncada S, Gryglewski R, Bunting S, Vane JR. An enzyme isolated from arteries transforms prostaglandin endoperoxides to an unstable substance that inhibits platelet aggregation. Nature $1976 ; 363: 663-5$.

${ }^{8}$ Davis TME, Bown E, Finch DR, Mitchell MD, Turner RC. In-vitro venous prostacyclin production, plasma 6-keto-prostaglandin $F_{1 \alpha}$ concentrations, and diabetic retinopathy. $\mathrm{Br}$ Med f 1981 ;282:1259-62.

9 Ylikorkala O, Kaila J, Viinikka L. Prostacyclin and thromboxane in diabetes. Br Med f 1981;283:1148-50.

${ }^{10}$ Herbert V, Lau KS, Gottlieb CW, Bleicher SJ. Coated charcoal immunoassay of insulin. $\mathcal{F}$ Clin Endocrinol Metab 1965;25:1375-84.

11 Fong JSC, Drummond KN. Method for preparation of glomeruli for metabolic studies. F Lab Clin Med 1968;71:1034-9.

12 Nolan RD, Dusting GJ, Martin TJ. Phospholipase inhibition and the mechanism of angiotensin-induced prostacyclin release from rat mesenteric vasculature. Biochem Pharmacol 1981;30:2121-5.

13 Brunk CF, Jones KC, James TW. Assay for nanogram quantities of DNA in cellular homogenates. Anal Biochem 1979;92:497-500.

14 Sraer J, Sraer JD, Chansel D, et al. Prostaglandin synthesis by isolated rat renal glomeruli. Mol Cell Endocrinol 1979;16:29-37.

15 Folkert VW, Schlondorff D. Prostaglandin synthesis in isolated glomeruli. Prostaglandins 1979;17:79-86.

16 Samuelsson B, Goldyne M, Granström G, et al. Prostaglandins and thromboxanes. Annu Rev Biochem 1978;47:997-1029.

17 Hoult JRS, Moore PK. Prostaglandin synthesis and inactivation in kidneys and lungs of rats with experimental diabetes. Clin Sci 1980;59:63-6.

18 Brown DM, Gerrard JM, Peller J, Rao GHR, White JG. Glomerular prostaglandin metabolism in diabetic rats. Diabetes $1980 ; 29$, suppl :55A.

(Accepted 26 fanuary 1982)

\title{
Chronic osteomyelitis due to Clostridium difficile
}

\author{
T V RILEY, K T KARTHIGASU
}

\begin{abstract}
Osteomyelitis caused by anaerobic bacteria is rarely reported, and a case of chronic osteomyelitis of the femur may be the first in which Clostridium difficile was the causative agent. The organism was isolated over several months and, although initially sensitive to penicillin, it developed resistance during this time. The organism's repeated isolation may have been due to the presence of resistant spores. Although the patient had no gastrointestinal symptoms the source of the organism was probably the patient's own gastrointestinal tract. Infection from the environment cannot, however, be excluded. Treatment was finally successful with metronidazole.
\end{abstract}

\section{Introduction}

With the exception of antibiotic-associated diarrhoea and pseudomembranous colitis Clostridium difficile is rarely a cause of infection. We describe a patient with chronic osteomyelitis of the femur due to this organism.

Department of Clinical Microbiology, University of Western Australia, Queen Elizabeth II Medical Centre, Nedlands, Western Australia 6009

T V RILEY, B APP SC, MASM, technologist

K T KARTHIGASU, PHD, FRCPA, clinical microbiologist

\section{Case report}

A 21-year-old man, who was injured in a motor accident while in Britain, sustained a fracture of the midshaft of the left femur which was treated with an open Kirschner nail. Eight months later, after his return to Australia, swelling developed over the injured site. He was admitted to hospital, where a large abscess surrounding the femoral shaft was drained. Microscopy of the pus showed numerous leucocytes but no organisms. Aerobic and anaerobic cultures were sterile. Treatment was started with cloxacillin $1 \mathrm{~g}$ intravenously and probenecid $500 \mathrm{mg}$ orally every six hours. He developed a discharging sinus and after eight weeks the wound was explored again. On exposure of the femoral shaft thick pus was seen; the wound was debrided, the infected area lavaged, and the Kirschner nail removed. Microscopy of the pus on this occasion showed numerous leucocytes and a few Grampositive bacilli. Culture produced a moderately heavy growth of a Clostridium species, initially thought to be $C$ sporogenes but later identified as $C$ difficile by the criteria of Holdeman et al..$^{1}$ The organism was shown to produce a toxin which was neutralised by $C$ sordellii antitoxin using a monolayer of VERO cells. The patient was treated with intravenous benzylpenicillin, $6 \mathrm{~g}$ daily, which was later increased to $8 \mathrm{~g}$ daily. Subsequently, a sinus appeared again, and a sinogram showed a large irregular cavity around the femoral shaft at the site of the fracture. Radiological investigations suggested osteomyelitis, and at a further operation a quantity of tissue and sequestrum was removed. Culture of bone and tissue again grew $C$ difficile. Over the next two months swabs from a discharging sinus consistently yielded $C$ difficile on either direct or enriched culture. Radiological changes over this period were consistent with chronic osteomyelitis and the patient was maintained on high doses of phenoxymethyl penicillin.

Up to this time the broth-disc dilution technique of Wilkins and Thiel ${ }^{2}$ had indicated that the organism was sensitive to $1.2 \mathrm{mg} / \mathrm{l}$ penicillin, and its repeated isolation was disconcerting. Since resistant spores were possibly being formed in vivo smears of discharging pus were stained by the Ziehl-Neelson method. Bacterial spores were present, even though vegetative organisms could not be detected. On the next occasion that $C$ difficile was isolated, however, it had developed resistance to phenoxymethyl penicillin; the minimum inhibitory 
concentration was $12.5 \mathrm{mg} / \mathrm{l}$. Treatment was changed to metronidazole $400 \mathrm{mg}$ three times daily and cultures rapidly ceased to grow $C$ difficile. The organism was not isolated over the succeeding 18 months and radiological changes suggested a resolving infection. The patient had no gastrointestinal symptoms at any time during the illness.

\section{Discussion}

Osteomyelitis caused by anaerobic bacteria is rare, and we are not aware of any previous reports of $C$ difficile causing this disease. $C$ difficile was first isolated by Hall and O'Toole, ${ }^{3}$ who found it to be part of the normal gastrointestinal flora of infants. Smith and $\mathrm{King}^{4}$ reported the isolation of $C$ difficile from several extraintestinal sites, and more recently it has been implicated as the causative agent of pseudomembranous colitis. ${ }^{5}$

The interesting features of this case are the unusual site of infection for this organism, the length of time over which the organism was isolated despite apparently appropriate treatment, and the development of penicillin resistance during treatment.

The source of the organism was probably the patient's own gastrointestinal tract, but the possibility of environmental infection cannot be excluded. Possibly the infection did not occur until after the initial drainage. The first abscess may have been sterile, as suggested by the first culture results, and merely a response to the foreign body present. It is unclear why the organism persisted for so long. On some occasions only very few organisms were present and thus enrichment media were required for isolation. The production of spores in vivo could explain the organism's persistence. The development of resistance to antibiotics during treatment is certainly not uncommon, and its occurrence in the present case added interest to an already interesting case. It is worth noting that transferable drug resistance in $C$ difficile has recently been reported. ${ }^{6}$

\section{References}

1 Holdeman LV, Cato EP, Moore WEC, eds. Anaerobe laboratory manual, 3rd ed. Blacksburg: Virginia Polytechnique Institute and State University, 1977.

2 Wilkins TD, Thiel T. Modified broth-disk method for testing the antibiotic susceptibility of anaerobic bacteria. Antimicrob Agents Chemother $1973 ; 3: 350-6$

${ }^{3}$ Hall IC, O'Toole E. Intestinal flora in new-born infants with a description of a new pathogenic anaerobe. Bacillus difficile. Am F Dis Child 1935;49: 390-402.

4 Smith LDS, King EO. Occurrence of Clostridium difficile in infections in man. $\mathcal{F}$ Bacteriol 1962;84:65-7.

${ }^{5}$ Bartlett JG, Chang TW, Taylor NS, Onderdonk AB. Colitis induced by Clostridium difficile. F Infect Dis 1979;1:370-8.

${ }^{6}$ Smith CJ, Markowitz SM, Macrina FL. Transferable tetracycline resistance in Clostridium difficile. Antimicrob Agents Chemother 1981;19: 997-1003.

(Accepted 27 fanuary 1982)

\title{
Twin pregnancy with complete hydatidiform mole $(46, \mathrm{XX})$ and fetus (46,XY): genetic origin proved by analysis of chromosome polymorphisms
}

\author{
ROSEMARY A FISHER, D M SHEPPARD, SYLVIA D LAWLER
}

\begin{abstract}
In a case of complete hydatidiform mole with fetus the genetic origins were defined by the use of chromosomal polymorphisms. The fetus had a normal $46, X Y$ karyotype with evidence of the presence of both maternal and paternal chromosomes. The mole was $46, \mathrm{XX}$ and of androgenetic origin. There was no evidence of a maternal contribution, and duplication of paternal chromosomes was shown.

In such atypical molar pregnancies examining genetic polymorphisms yields much more information than do sex chromosome studies and karyotyping, particularly in confirming the diagnosis and defining the origin and aetiology of the condition.
\end{abstract}

\section{Introduction}

Hydatidiform mole may be separated into two entities on the basis of histopathology, ${ }^{12}$ cytogenetics, ${ }^{3-8}$ and biochemical

\footnotetext{
Institute of Cancer Research and the Royal Marsden Hospital, London SW3 6JJ

ROSEMARY A FISHER, MPHIL, biochemist

D M SHEPPARD, BSC, senior technician

SYLVIA D LAWLER, MD, FRCPATH, professor of human genetics
}

markers. ${ }^{5} 7$ Complete moles lack the presence of a fetus, are almost always female, and are androgenetic in origin. ${ }^{3-5}$ ? In contrast, partial moles have a range of villi from normal to hydatidiform, focal rather than conspicuous hyperplasia, and evidence for the presence of a fetus. ${ }^{2}$ When karyotype analysis of the placenta and fetus has been carried out partial moles have generally been found to be triploid. ${ }^{16-10}$ Cases of mole with coexistent fetus must now be assessed in the light of these findings.

\section{Patient and methods}

The patient was a 27-year-old woman who had given birth to a normal girl in 1972 and a normal boy in 1976. She presented in her third pregnancy at eight and a half weeks of gestation with a uterus size of 14 weeks. Ultrasound examination showed the presence of a fetus. When she was seen again three weeks later with painless vaginal bleeding and an enlarged uterus no fetus was detected on scanning. The pregnancy was terminated by suction evacuation at $15 \frac{1}{2}$ weeks because of a suspected mole.

Macroscopic examination of the specimen showed a large mass of molar tissue comprising clusters of translucent thin-walled cysts ranging from 2 to $20 \mathrm{~mm}$ in size, encased in clotted blood. A small portion of apparently normal placenta associated with some membranous material was seen and appeared to be separate from the main bulk of the vesicular mass. Also present was a partially macerated male fetus with a crown-rump length of $4.5 \mathrm{~cm}$ and a foot length of $6 \mathrm{~mm}$, and therefore estimated to be between 8 and 10 weeks of gestational age. Further examination showed no external abnormalities, all limbs being present and with the normal number of digits. On dissection no abnormalities were detected in the internal organs. 